\section{How to meet the challenges of managing patients with IBS}

\author{
Establish a strong relationship with your patient. Rule \\ out "red-flag" diagnoses. Then choose from one of the \\ therapies detailed here to target the subtype of disease.
}

\section{PRACTICE RECOMMENDATIONS \\ $>$ Make the diagnosis of \\ I} irritable bowel syndrome (IBS) based on clinical findings, after excluding red flags in the presentation. (C)

> Screen patients with diarrhea-predominant IBS with fecal and serologic studies to rule out inflammatory bowel disease and celiac disease. B

$>$ Counsel all IBS patients to increase their intake of soluble fiber, follow a low-FODMAP (fermentable oligo-, di-, and monosaccharide, and polyol) diet, and increase physical activity. (B)

$>$ Prescribe an antispasmodic to treat mild IBS of all subtypes. B

Strength of recommendation (SOR) A Good-quality patient-oriented
evidence (B) Inconsistent or limited-quality
patient-oriented evidence

C Consensus, usual practice, opinion, disease-oriented evidence, case series rritable bowel syndrome (IBS) continues to pose a diagnostic and therapeutic challenge to clinicians and patients - a challenge that arises from the varying manifestations of the condition, its complex pathophysiology, lack of effective treatment, and psychological consequences for patients. In this article, I explore new findings related to the pathophysiology, diagnosis, and management of IBS subtypes.

\section{Start with the Rome IV \\ classification of IBS}

The Rome Foundation published its latest IBS classification and diagnostic criteria (known as Rome IV) in 2016. ${ }^{1}$ IBS is defined as abdominal pain that (1) has recurred, on average, $\geq 1$ time per week during the past 3 months and (2) is associated with $\geq 2$ of these criteria ${ }^{1}$ :

- related to defecation

- associated with a change in stool frequency

- associated with a change in the appearance of stool.

Onset of symptoms should be present for 6 months before a diagnosis of IBS is made. ${ }^{1}$

IBS subtypes-constipation-predominant(IBS-C), diarrheapredominant (IBS-D), mixed (IBS-M), and unclassified (IBS-U) (TABLE 1) ${ }^{1}$-are based on the frequency of specific stool forms, as described and illustrated in the Bristol Stool Scale (www.webmd. com/digestive-disorders/poop-chart-bristol-stool-scale). ${ }^{2}$

A widespread, costly, potentially debilitating disorder

IBS affects $10 \%$ to $12 \%$ of adults worldwide. The condition is more common among women and people younger than 50 years. ${ }^{1,3}$ Women with IBS tend to have more constipation symptoms (IBS-C); men with IBS, more diarrhea symptoms (IBS-D). ${ }^{4}$
Jose M. Villalon-Gomez MD, MPH

Department of Family and Preventive Medicine, Emory University, Atlanta, GA

Dijose.villalon-gomez@ emory.edu

The author reported no potential conflict of interest relevant to this article. doi: $10.12788 / \mathrm{jfp} .0299$ 
TABLE 1

Classification of IBS subtypes based on the Rome IV criteria ${ }^{1}$

\begin{tabular}{|c|c|}
\hline Subtype & Description \\
\hline Constipation-predominant IBS & $\begin{array}{l}>25 \% \text { of bowel movements are Bristol stool form Type } 1 \text { (separate hard lumps) } \\
\text { or Type } 2 \text { (lumpy and sausage-like) } \\
\text { and } \\
<25 \% \text { of bowel movements are Bristol stool form Type } 6 \text { (mushy consistency with } \\
\text { ragged edges) or Type } 7 \text { (liquid consistency with no solid pieces) }\end{array}$ \\
\hline Diarrhea-predominant IBS & $\begin{array}{l}>25 \% \text { of bowel movements are Bristol stool form Type } 6 \text { or Type } 7 \\
\text { and } \\
<25 \% \text { of bowel movements are Bristol stool form Type } 1 \text { or Type } 2\end{array}$ \\
\hline Mixed IBS & $\begin{array}{l}>25 \% \text { of bowel movements are Bristol stool form Type } 1 \text { or Type } 2 \\
\text { and } \\
>25 \% \text { of bowel movements are Bristol stool form Type } 6 \text { or Type } 7\end{array}$ \\
\hline Unclassified IBS & $\begin{array}{l}\text { Meets diagnostic criteria for IBS, but bowel habits cannot be categorized as } \\
\text { constipation-predominant IBS, diarrhea-predominant IBS, or mixed IBS }\end{array}$ \\
\hline
\end{tabular}

IBS, irritable bowel syndrome.

The financial burden of IBS on the health care system and patients is significant. In a 2013 appraisal of 35 studies, the authors note that estimates of the direct cost of IBS care in the United States vary considerably-from $\$ 1562$ to $\$ 7547$ for a patient annually. ${ }^{5}$

A recent study found that almost $25 \%$ of IBS patients report absenteeism from work due to IBS symptoms. ${ }^{6}$ A Danish study that followed 7278 patients for 5 years found that IBS patients utilized more health care, sick days, and disability pension benefits than non-IBS patients, and had increased utilization of medical resources because of psychiatric conditions. ${ }^{7}$

IBS patients also have comorbidities:

- More than $20 \%$ of IBS patients have functional dyspepsia, gastroesophageal reflux disease, incontinence, or pelvic floor dyssynergia. ${ }^{4}$

- The frequency of fibromyalgia syndrome in IBS patients is reported to be $20 \%$ to $65 \% .^{8}$

- $14 \%$ of IBS patients meet criteria for chronic fatigue syndrome. ${ }^{8}$

- Interstitial cystitis and dyspareunia are common among IBS patients. ${ }^{9}$

\section{Pathophysiology is complex}

Models describing the pathophysiology of IBS have evolved through the years. Recent models describe it as a combination of altered gastrointestinal motility, visceral hyperalgesia, increased intestinal permeability, immune activation, altered intestinal microbiota, and dysfunction in the brain-gut axis. Certain environmental and psychological variables (eg, previous gastroenteritis, food intolerance, chronic stress, diverticulitis, and surgery) increase the risk of IBS. ${ }^{1,10,11}$

In the past several years, considerable attention has been paid to the roles played by the immune system, brain-gut axis function, and intestinal microbiota in IBS manifestations. Research focus in these areas might assist in the development of specific treatment modalities targeting IBS subtypes.

IImmune system. A recent metaanalysis of the records of 706 IBS patients found an increased number of mast cells and CD3 $\mathrm{T}$ cells in biopsy specimens from the rectosigmoid and descending colon of IBS patients. ${ }^{12}$ Another study found a significant increase in mast cells in the ileum of IBS patients ${ }^{13}$; this increase is evident not only on intestinal biopsy but also at the serologic level. IBS-D patients have a higher plasma interleukin (IL)-6 level than the general population. ${ }^{14}$ Another meta-analysis found an imbalance in the serum level of tumor necrosis factor- $\alpha$ and IL-10 in IBS patients. ${ }^{15}$

I Brain-gut axis. A 2016 meta-analysis showed that patients with anxiety and de- 
pression have a 2 -fold increased risk of IBS. ${ }^{16}$ A more recent study, using data from the National Health Insurance Research Database that included 22,356 patients with IBS, found a 3.6-fold increased risk of psychiatric disorders in IBS. ${ }^{17}$ These findings reflect the complex interaction between the brain and the intestinal tract in IBS.

I Intestinal microbiota. Research evaluating the role of altered intestinal microbiota in IBS has yielded mixed results. A meta-analysis of 777 IBS patients showed an increase in Firmicutes spp, a decrease in Bacteroidetes spp, and an increase in the ratio of Firmicutes spp to Bacteroidetes spp in subjects' fecal specimens. ${ }^{18}$ Another study, of 1340 patients, found no difference in Bacteroides spp and Enterococcus spp between healthy controls and IBS patients, but did find (1) lower fecal counts of Lactobacillus spp and Bifidobacterium spp and (2) higher fecal counts of Escherichia coli and Enterobacter spp in IBS patients. ${ }^{19}$

I Postinfectious IBS. The Rome Foundation introduced the diagnosis of postinfectious IBS (PI-IBS) in 2019. PI-IBS develops in $10 \%$ of patients who have had infectious enteritis. Female gender, younger age, psychological distress during or before the enteritis episode, and severity of the acute episode are risk factors for this IBS variant. ${ }^{20} \mathrm{~A}$ study of 21,421 enteritis patients found that $42 \%$ with protozoal or parasitic infection and $14 \%$ with bacterial infection developed IBS.

Patients with nonviral enteritis often have a more severe course of enteritis, typically requiring antibiotics. It is believed that the resulting irregularities in the intestinal microbiota make these patients more likely to develop PI-IBS. ${ }^{21}$ PI-IBS patients are likely to improve or fully recover over time. Symptoms of PI-IBS are managed in a manner similar to how non-PI-IBS patients are managed. ${ }^{20}$

\section{Challenges in making the IBS diagnosis}

Historically, the diagnosis of IBS has been made clinically after excluding red flags (ie, signs or symptoms that might reflect other underlying medical problems) in the clinical presentation. For this reason, obtain a thor- ough clinical history that includes the course of symptoms, triggers, and alleviating factors. Any of the following are considered red flags $^{1,22,23}$ :

- age $>50$ years at onset of symptoms

- new-onset constipation in the elderly

- rectal bleeding

- unexplained weight loss or anemia

- family history of organic gastrointestinal disease

- palpable abdominal or rectal mass

- nocturnal symptoms.

New studies demonstrate that several inflammatory markers can help exclude inflammatory bowel disease from the differential diagnosis in patients in whom IBS is suspected and being investigated. ${ }^{24}$ In 2019, the American Gastroenterological Association published a clinical practice guideline updating the laboratory evaluation of functional diarrhea and IBS-D in adults, ${ }^{25}$ and made several recommendations:

- Obtain the level of fecal calprotectin (normal level, $\leq 50 \mathrm{mcg} / \mathrm{g}$ ) or fecal lactoferrin $(\leq 4.0-7.25 \mathrm{mcg} / \mathrm{g})$; if these tests are not available or results are not accessible, the C-reactive protein level is a reasonable option.

- Do not routinely use the erythrocyte sedimentation rate or C-reactive protein level to screen for inflammatory bowel disease.

- Test for Giardia lamblia with an antigen or polymerase chain reaction test.

- Do not test for ova and parasites (other than Giardia) in patients who do not have a history of travel or who have not emigrated from a high-risk area recently.

- Obtain testing for celiac disease with immunoglobulin A (IgA) tissue transglutaminase and with a second test, of immunoglobulin G (IgG) tissue transglutaminase and IgG or IgA deaminated gliadin peptides, to detect celiac disease in IgA-deficient patients.

- Order testing for bile-acid diarrhea with selenium homotaurocholic acid nuclear medicine scanning (if available in your region; the test is available in Europe); measurement of bile acid

\section{$>$}

To identify possible "red flags" or other disorders, take a history that includes the course of symptoms, triggers, and alleviating factors. 


\section{Low cost and low risk of adverse effects makes exercise worth recommending to all IBS patients.}

from a 48-hour stool collection; or an assay of fibroblast growth factor 19, which measures defective feedback of bile-acid synthesis. If these tests are unavailable, consider an empiric trial of a bile-acid binder.

- Do not use available serologic IBS testing.

Continue to obtain a complete blood count for the evaluation of anemia. Endoscopic procedures are indicated in patients with a red flag. ${ }^{1}$

\section{Treat based on subtype}

The first step in the treatment of all IBS patients (TABLE $\mathbf{2}^{1,3,4,9,26,27}$ ) is for you to develop a strong relationship with the patient: You must acknowledge the disease and empower the patient to manage their symptoms. A strong physician-patient relationship leads to more effective outcomes. ${ }^{4}$

IBS treatment modalities target abdominal pain, bloating, abdominal distention, and altered bowel function-described in the literature as global symptoms. IBS-M patients should direct their treatment to the predominant symptom (constipation or diarrhea). The following sections describe available treatment options. The FIGURE ${ }^{1,3,4,9,25}$ shows a treatment workflow based on IBS subtype and symptom severity.

\section{Treatments for all IBS subtypes}

I Lifestyle modification. Exercise provides overall positive health benefits. With such a variety of exercise forms, however, it is difficult to identify specific exercises that are better for IBS patients. ${ }^{28} \mathrm{~A}$ study of 305 IBS patients found that exercise alleviated constipation but not other IBS symptoms, and did not improve quality of life. ${ }^{3}$ Based on low cost and low risk of adverse effects, exercise should be recommended to all IBS patients.

I Dietary restriction therapies have become an area of focus for patients, clinicians, and researchers. Modification of the diet is thought to improve global symptoms and intestinal health through modification of gut microbiota, immune activation, and a decrease in levels of fecal short-chain fatty acids. ${ }^{29}$
The 2 main diets studied for the treatment of IBS are a diet low in fermentable oligo-, di- and monosaccharides and polyols-the so-called low-FODMAP diet $\left(\right.$ TABLE $3^{30}$ ) - and a gluten-free diet. Evidence behind the benefits of both diets conflicts; trials of the low-FODMAP diet are more favorable.

A small study with 20 patients with IBS-D and IBS-M who followed a low-FODMAP diet found improvement in IBS symptoms and a reduction in serum levels of proinflammatory cytokines, fecal bacteria, and total fecal short-chain fatty acid levels. ${ }^{29}$ Several metaanalyses have shown improvement in overall IBS symptoms for patients who follow a lowFODMAP diet. Because of the heterogeneity of the studies, however, the quality of the data is low. ${ }^{31-34}$

Data supporting the use of a gluten-free diet for IBS patients are insufficient. ${ }^{31}$

The American College of Gastroenterology (ACG) gave a weak recommendation for the low-FODMAP diet and recommended against the gluten-free diet in IBS patients. ${ }^{3}$ More data are needed regarding the safety profile of using a low-FODMAP diet for an extended period: There is concern about the risk of nutritional deficiencies associated with long-term use of this diet. ${ }^{3}$

Supplementation with poorly fermentable soluble fiber has been shown to alleviate global IBS symptoms; insoluble fiber does not yield improvement of symptoms. Psyllium fiber is recommended over wheat bran. ${ }^{3,35}$

Consider a low-FODMAP diet and soluble fiber as initial treatment for all IBS patients.

I Modification of intestinal microbiota. Understanding the difference between prebiotics and probiotics is important when considering treatment for IBS. Prebiotics are foods or dietary supplements that generate changes in the composition and activity of intestinal microbiota. Probiotics are live microorganisms that can improve intestinal health. ${ }^{3}$

A meta-analysis of 729 IBS patients found that prebiotics do not reduce gastrointestinal symptoms or improve the quality of life of IBS patients. ${ }^{36}$ Evidence supporting the benefit of probiotics is favorable; however, data in 
TABLE 2

Treatment options for IBS, based on symptoms $s^{1,3,4,9,26,27}$

\begin{tabular}{|c|c|c|}
\hline Symptom & Drug class ${ }^{\mathrm{a}}$ & Agent and dosage \\
\hline \multirow[t]{4}{*}{ Diarrhea } & Antibiotic & Rifaximin $550 \mathrm{mg}$ orally tid for $2 \mathrm{wk}$ \\
\hline & Bile-acid sequestrants ${ }^{b}$ & $\begin{array}{l}\text { Cholestyramine } 9 \mathrm{~g} \text { bid or tid } \\
\text { Colestipol } 2 \mathrm{~g} \text { qd or bid } \\
\text { Colesevelam } 625 \mathrm{mg} \text { qd or bid }\end{array}$ \\
\hline & $5-\mathrm{HT}_{3}$ receptor antagonists & $\begin{array}{l}\text { Alosetron } 0.5-1 \mathrm{mg} \mathrm{bid} \\
\text { Ondansetron } 4-8 \mathrm{mg} \mathrm{tid}^{\mathrm{b}}\end{array}$ \\
\hline & Mixed opioid agonist-antagonist & Eluxadoline $100 \mathrm{mg}$ bid \\
\hline \multirow[t]{5}{*}{ Constipation } & Chloride channel type 2 activator & Lubiprostone $8 \mathrm{mcg}$ bid \\
\hline & Fiber & Poorly fermentable soluble fiber \\
\hline & Guanylate cyclase- $C$ agonist & $\begin{array}{l}\text { Linaclotide } 290 \mathrm{mcg} \text { qd } \\
\text { Plecanatide } 3 \mathrm{mg} \mathrm{qd}\end{array}$ \\
\hline & $5-\mathrm{HT}_{4}$ receptor agonist & Tegaserod $6 \mathrm{mg}$ bid \\
\hline & Sodium-hydrogen exchanger 3 inhibitor & Tenapanor $50 \mathrm{mg}$ bid \\
\hline \multirow[t]{12}{*}{ Abdominal pain } & Antispasmodics & $\begin{array}{l}\text { Dicyclomine } 20 \mathrm{mg} \text { qid } \\
\text { Hyoscyamine } 0.125-0.25 \mathrm{mg} \text { qid }\end{array}$ \\
\hline & Chloride-channel type 2 activator & Lubiprostone $8 \mathrm{mcg}$ bid \\
\hline & Diet & Low-FODMAP diet \\
\hline & Fiber & Poorly fermentable soluble fiber \\
\hline & Guanylate cyclase- $\mathrm{C}$ agonist & $\begin{array}{l}\text { Linaclotide } 290 \mathrm{mcg} \text { qd } \\
\text { Plecanatide } 3 \mathrm{mg} \mathrm{qd}\end{array}$ \\
\hline & $5-\mathrm{HT}_{3}$ receptor antagonist & Alosetron $0.5-1 \mathrm{mg}$ bid \\
\hline & $5-\mathrm{HT}_{4}$ receptor agonist & Tegaserod $6 \mathrm{mg}$ bid \\
\hline & Peppermint oil ${ }^{b}$ & $\begin{array}{l}\text { Enteric-coated tablets } 250-750 \mathrm{mg} \\
\text { bid or tid }\end{array}$ \\
\hline & Probiotics & $\begin{array}{l}\text { Numerous products are available; } \\
\text { strains of bacteria and numbers } \\
\text { of colony-forming units vary from } \\
\text { product to product }\end{array}$ \\
\hline & Selective serotonin reuptake inhibitors & $\begin{array}{l}\text { Citalopram } 10-40 \mathrm{mg} \text { qd } \\
\text { Paroxetine } 10-40 \mathrm{mg} \text { qd } \\
\text { Sertraline } 25-100 \mathrm{mg} \text { qd }\end{array}$ \\
\hline & Sodium-hydrogen exchanger 3 inhibitor & Tenapanor $50 \mathrm{mg}$ bid \\
\hline & Tricyclic antidepressants & $\begin{array}{l}\text { Desipramine } 25-100 \mathrm{mg} \text { every night } \\
\text { at bedtime } \\
\text { Amitriptyline } 10-50 \mathrm{mg} \text { every night } \\
\text { at bedtime }\end{array}$ \\
\hline
\end{tabular}

FODMAP, fermentable oligo-, di-, and monosaccharides and polyols; IBS, irritable bowel syndrome.

a In alphabetical order, by drug class.

${ }^{b}$ Not approved by the US Food and Drug Administration for treating irritable bowel syndrome.

'Not commercially available in the United States; available in Canada.

Consider recommending probiotics for all IBS patients, although high cost might be an obstacle for some. 
FIGURE

\section{Treatment ${ }^{\mathrm{a}}$ workflow for IBS, based on subtype and symptom severity ${ }^{1,3,4,9,25}$}

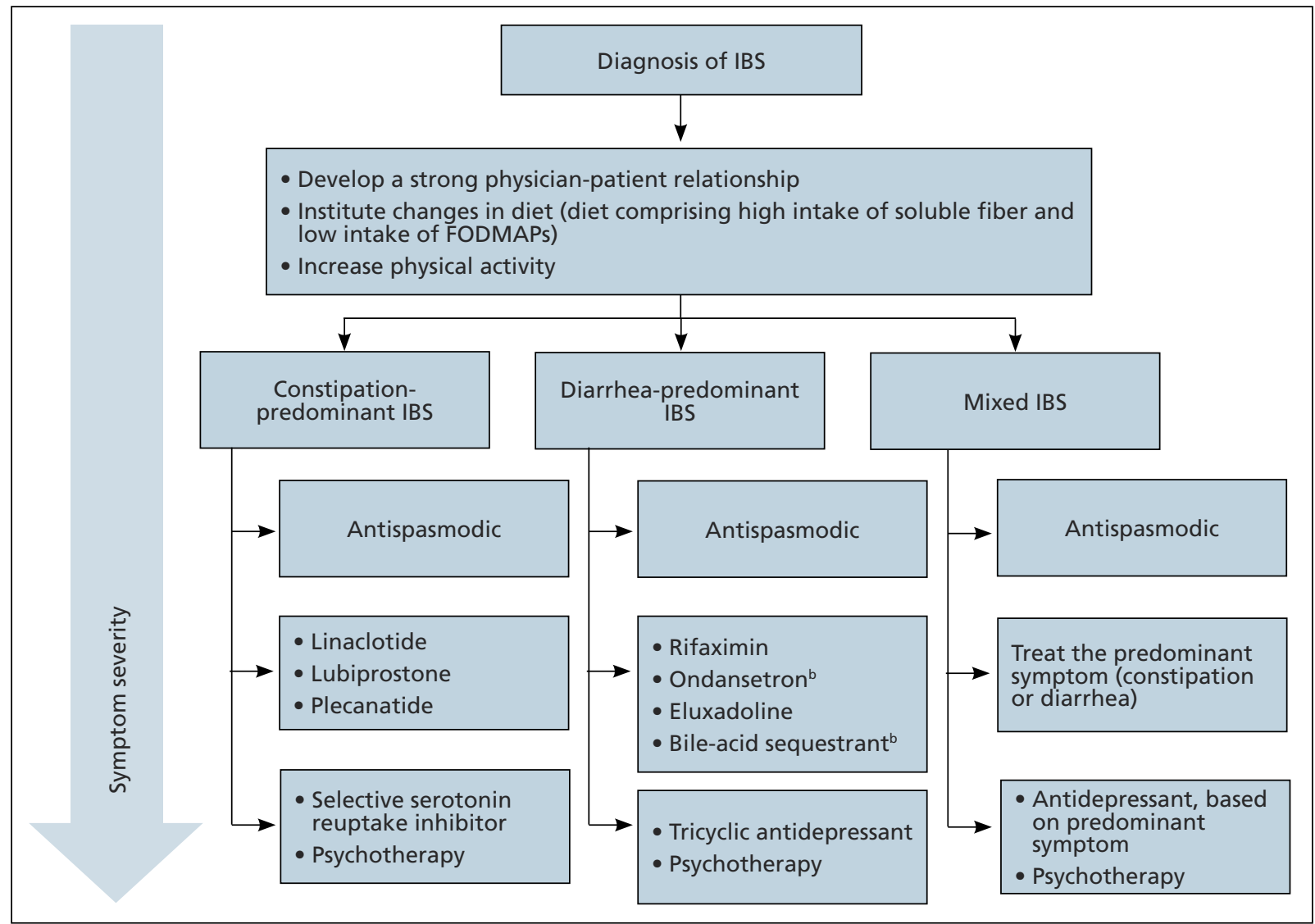

FODMAPs, fermentable oligo-, di-, and monosaccharides and polyols; IBS, irritable bowel syndrome.

a Medications and other interventions are listed within cells in order of line of treatment (ie, first-line, second-line, etc).

${ }^{b}$ Not approved by the US Food and Drug Administration for the treatment of diarrhea-predominant IBS.

these studies have significant heterogeneity. Several meta-analyses studied the benefits of Lactobacillus spp and Bifidobacterium spp in alleviating IBS symptoms. The studies found improvement in abdominal pain, bloating and distention, and flatulence. ${ }^{3,37-40}$ Consider recommending probiotics for all IBS patients; for some, however, the high cost of some of these products might be an obstacle.

Researchers are also studying the use of fecal microbiota transplantation (FMT) to treat IBS. Studies have evaluated the delivery of FMT orally (as capsules) and endoscopically. Evidence does not show improvement in global IBS symptoms with FMT. More studies, with larger sample populations, are needed. ${ }^{41-43}$

Intispasmodic medications and peppermint oil. Antispasmodic medications have been considered a mainstay therapy for IBS because of their effect on intestinal dysmotility. Hyoscine and dicyclomine are commonly used. Meta-analyses have shown improvement in global symptoms and abdominal pain, but effects were modest. ${ }^{3,44}$ Use this class of drugs as first-line treatment for mild IBS symptoms.

Peppermint oil has been found useful in improving IBS global symptoms and abdominal pain in several studies. ${ }^{44-46} \mathrm{~A}$ common adverse effect of peppermint oil is heartburn, resulting from relaxation of esophageal muscle. ${ }^{3}$ Peppermint oil can be considered an adjuvant agent in treating IBS.

I Antidepressants. Tricyclic antidepressants (TCAs) and selective serotonin reuptake inhibitors (SSRIs) have been studied for 
TABLE 3

Foods and additives to avoid with a low-FODMAP diet ${ }^{30}$

\begin{tabular}{|c|c|c|c|c|}
\hline Fructose & Lactose & Polyols & Fructans & Galactans \\
\hline Apple & Cheese & Apple & Asparagus & Cashew \\
\hline Artichoke & Condensed milk & Apricot & Brussels sprout & Chickpea \\
\hline Asparagus & Custard & Cauliflower & Garlic & Legumes \\
\hline Dried fruit & Evaporated milk & Isomalt & Onion & Lentil \\
\hline Fruit juice & Ice cream & Longan (fruit) & Rye & Pistachio \\
\hline High-fructose corn & Milk & Lychee & Wheat & \\
\hline syrup & Yogurt & Maltitol & & \\
\hline Honey & & Mannitol & & \\
\hline Mango & & Mushrooms & & \\
\hline Pear & & Nashi pear & & \\
\hline Sugar snap pea & & Nectarine & & \\
\hline Watermelon & & Peach & & \\
\hline & & Pear & & \\
\hline & & Plum & & \\
\hline & & Snow pea & & \\
\hline & & Sorbitol & & \\
\hline & & Xylitol & & \\
\hline
\end{tabular}

FODMAP, fermentable oligo-, di-, and monosaccharides and polyols.

the treatment of IBS. Meta-analyses show that both are effective in reducing pain and overall IBS symptoms. ${ }^{1,3,47}$ The number needed to treat (NNT) for TCAs is 4.5; for SSRIs, $5 .{ }^{47}$ Data do not show that either drug class is superior to the other for IBS. Based on the adverse effect profile, TCAs are more suitable for IBS-D patients; SSRIs are better for IBS-C patients. ${ }^{47}$

New data show that serotoninnorepinephrine reuptake inhibitors, such as duloxetine and milnacipran, can alleviate IBS symptoms through their pain-modifying properties. ${ }^{47}$

Based on the adverse effect profile and stigma associated with antidepressant medications, patients might be less likely to take them for IBS symptoms than for these drugs' primary indications. Clinicians should still consider this drug class if other first-line treatments do not provide full resolution of symptoms.

I Psychotherapy. Several psychotherapeutic modalities have been evaluated for efficacy in reducing global IBS symptoms.
The approaches studied most often were provider-directed cognitive behavioral therapy, relaxation therapy, hypnotherapy, and multicomponent psychological therapy. The NNT for these modalities is 4 , but studies had significant heterogeneity. ${ }^{3}$ Consider referring patients for psychotherapeutic intervention if they have not responded to medical therapy after 12 months. ${ }^{4}$

\section{Treatment of IBS-C}

I Prosecretory agents. Linaclotide and plecanatide are amino-acid peptides that act as a guanylate cyclase $\mathrm{C}$ agonist. Both increase gastrointestinal transit rate by increasing electrolyte and fluid transport into the intestinal lumen. They also decrease the activity of pain-sensing nerves by increasing extracellular cyclic guanosine-3'5'-monophosphate levels. ${ }^{3,48}$ In a recent meta-analysis, both treatments produced improvement in global symptoms. However, linaclotide showed superior improvement in abdominal pain and global symptoms compared to other secreto- 


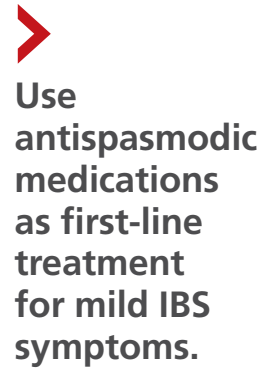

Use asmodic ations -line for mild IBS symptoms. ry agents. ${ }^{48,49}$ Diarrhea was the most common adverse effect of linaclotide and plecanatide, although less so with plecanatide. ${ }^{49}$

Lubiprostone activates the intestinal chloride channel type 2 on the small intestine, leading to an increase in chloride and water efflux into the intestinal lumen, in turn accelerating gastrointestinal transit. ${ }^{3} \mathrm{~A}$ meta-analysis with 1468 IBS patients found that lubiprostone improved constipation, stool consistency, abdominal pain, degree of straining, and abdominal bloating. ${ }^{50}$ Diarrhea and nausea are commonly reported adverse effects of lubiprostone..$^{49,50}$

Linaclotide, plecanatide, and lubiprostone should be considered first-line therapies for patients with IBS-C. High cost is still a roadblock to the use of these agents.

The US Food and Drug Administration (FDA) approved tenapanor in September 2019; however, the drug is not commercially available in the United States (it is available in Canada). Tenapanor is a sodium-hydrogen exchanger 3 inhibitor that reduces sodium absorption from the intestine and colon. The drug increases water secretion into the intestinal lumen, thus accelerating gut transit time. It also inhibits active absorption of phosphate in the intestine.

Tenapanor was approved for treating both IBS-C and hyperphosphatemia in patients with chronic kidney disease on dialysis or end-stage renal disease. ${ }^{26}$ In a recent metaanalysis, the drug showed benefit in alleviating global IBS symptoms, and ranked first in reducing bloating. ${ }^{49}$ It is too soon to know if tenapanor will perform clinically better than other prosecretory agents.

I Serotonergic agents. Serotonin (5-hydroxytryptamine [5-HT]) modulates gastrointestinal secretions, gut motility, and visceral sensation. Researchers have developed IBS treatments that target receptors involved in these functions.

Tegaserod is a partial, selective $5-\mathrm{HT}_{4}$ agonist indicated for the treatment of IBS-C in women. A study with 661 women with IBS-M and IBS-C showed that tegaserod increased the number of bowel movement episodes. Patients also reported higher stool consistency scores and fewer days with straining compared to placebo. ${ }^{27}$ The medication was removed from the market in 2007 because of its potential for cardiovascular adverse effects $^{3}$; however, it was reintroduced in 2019 for women $<65$ years of age with IBS-C. Consider prescribing tegaserod if other treatment options fail to alleviate symptoms.

\section{Treatment of IBS-D}

Antibiotics. The nonabsorbable antibiotic rifaximin is approved by the FDA for IBS-D at a dosage of $550 \mathrm{mg}$ tid for 2 weeks. ${ }^{1} \mathrm{Sev}$ eral studies show improvement in IBS global symptoms with the recommended treatment course $^{51-53}$; benefit persisted for the 10-week follow-up study period. ${ }^{1}$ A meta-analysis found that the NNT for rifaximin is 8-11. ${ }^{54}$ Preliminary data indicate that the rates of Clostridioides difficile infection and microbial resistance among rifaximin users are low. ${ }^{3}$ Consider using rifaximin as a first-line treatment option for patients with IBS-D. Retreatment might be necessary because the drug's effect gradually disappears. ${ }^{9}$

Antidiarrheals. Eluxadoline is a $\mu$-opioid and $\kappa$-opioid receptor agonist and $\delta$-opioid receptor antagonist with effects on the intestinal nervous system. ${ }^{3}$ Several meta-analyses demonstrated that eluxadoline improves abdominal pain scores and daily stool consistency in IBS-D patients. ${ }^{53,54}$ Eluxadoline should be considered early in the management of IBS-D patients. The most common adverse effect is constipation.

The FDA issued a safety warning in 2017 regarding an increased risk of pancreatitis in patients taking eluxadoline who do not have a gallbladder. In addition, eluxadoline should be avoided in patients with a history of sphincter of Oddi dysfunction, alcohol abuse, or severe liver problems. ${ }^{3,54}$

The high cost of eluxadoline can be a significant barrier to use.

I Serotonergic agents. Alosetron is a selective $5-\mathrm{HT}_{3}$ antagonist developed to treat IBS-D. ${ }^{3}$ In a meta-analysis comprising 9844 patients, alosetron showed superior abdominal pain scores and improved stool consistency compared to ramosetron, rifaximin, and eluxadoline..$^{53}$ In 2001, the FDA withdrew alosetron, due to severe constipation and a risk of ischemic colitis; however, the medication has become commercially available 
again through a risk evaluation and mitigation strategy (REMS) program for women who have disabling IBS-D symptoms. ${ }^{3,54}$ Because of this special circumstance, alosetron is not considered first-line therapy for IBS-D.

Ondansetron has also been used to treat IBS-D. In a meta-analysis with 294 patients, ondansetron showed improvement in stool consistency. ${ }^{55}$ Ondansetron does not improve abdominal pain. ${ }^{4}$ It can be used in patients who have mild-to-moderate symptoms. ${ }^{9}$ Ondansetron is not FDA approved for the treatment of IBS-D.

I Bile-acid sequestrants. Traditionally, bile-acid sequestrants have been used to treat bile-acid diarrhea. A meta-analysis of 6 studies of 908 patients with IBS-D found that $28.1 \%$ were affected by bile-acid malabsorption. Two small studies that evaluated the benefits of colesevelam for IBS-D found significant improvement in stool consistency. ${ }^{54}$ Another study, which evaluated the benefits of cholestyramine, found improvement in stool consistency, but findings were not significant. ${ }^{54}$ Many patients taking a bileacid sequestrant stop taking the medication because of considerable adverse effects (constipation, nausea, bloating, flatulence, and abdominal pain).$^{54}$ For that reason, this class of medication is not recommended as firstline treatment for IBS-D and is not FDA approved for IBS-D.

\section{A role for complementary} and integrative medicine?

Recently, complementary and integrative modalities for treating IBS have sparked the interest of researchers.

I Acupuncture. In a meta-analysis with 3440 patients, acupuncture was more effective than Western medicine in alleviating IBS symptoms for as long as 3 months. The authors concluded that acupuncture could be used in combination with other therapies to reduce the severity of IBS symptoms. ${ }^{56}$

I Concomitant acupuncture and Chinese herbal medicine. In a systematic review and meta-analysis comprising 21 randomized controlled trials, researchers reported that acupuncture combined with Chinese herbal medicine improved IBS symptoms, compared to what was noted in matched

\section{KEY POINTS}

\section{The challenge of, and a needed framework for, managing IBS}

- IBS is a complex, chronic condition affecting a considerable number of people worldwide.

- Because of the substantial disease burden associated with IBS, patients are at higher risk of mental health disorders.

- Physicians who care for IBS patients must build a strong physician-patient relationship; their mutual trust will ensure development of an effective treatment plan.

- Family physicians and other primary care providers are equipped to help IBS patients navigate the complex health care system and the IBS disease process. They can help coordinate care with specialists and behavioral health clinicians, which will help patients improve quality of life and manage symptoms appropriately.

controls who were treated with Western medicine or with Western medicine combined with Chinese herbal medicine. The authors were cautious about the results of the metaanalysis, however, because the studies examined were small and of low quality, and presented a high risk of bias. ${ }^{57}$

\section{Agents not to be used routinely for IBS}

I Loperamide. This peripheral $\mu$-opioid receptor agonist controls diarrhea. However, recent studies showed no significant benefit to loperamide over placebo in IBS-M and IBS-D. In 2018, the FDA issued a safety alert regarding an elevated risk of serious cardiac adverse effects in patients taking loperamide. The ACG recommends against using loperamide to treat IBS symptoms. ${ }^{3,54}$

I Polyethylene glycol. An osmotic laxative that is not absorbed in the intestinal lumen, polyethylene glycol is highly efficacious for alleviating constipation, but it does not reduce pain or other IBS symptoms. For that reason, the ACG recommends against its use. ${ }^{3}$ 


\section{References}

1. Lacy BE, Mearin F, Chang L, et al. Bowel disorders. Gastroenterology. 2016;150:1393-1407.e5. doi:10.1053/j.gastro.2016.02.031

2. What kind of poop do I have? WebMD. January 16, 2020. Accessed September 20, 2021. www.webmd.com/digestive-disorders/ poop-chart-bristol-stool-scale

3. Ford AC, Moayyedi P, Chey WD, et al; ACG Task Force on Management of Irritable Bowel Syndrome. American College of Gastroenterology monograph on management of irritable bowel syndrome. Am J Gastroenterol. 2018;113(suppl 2):1-18. doi:10.1038/ s41395-018-0084-x

4. Ferreira AI, Garrido M, Castro-Poças F. Irritable bowel syndrome: news from an old disorder. GE Port J Gastroenterol. 2020;27: 255-268. doi:10.1159/000503757

5. Black CJ, Ford AC. Global burden of irritable bowel syndrome: trends, predictions and risk factors. Nat Rev Gastroenterol Hepatol. 2020;17:473-486. doi: 10.1038/s41575-020-0286-8

6. Frändemark $\AA$, Törnblom $\mathrm{H}$, Jakobsson $\mathrm{S}$, et al. Work productivity and activity impairment in irritable bowel syndrome (IBS): a multifaceted problem: Am J Gastroenterol. 2018;113:1540-1549. doi:10.1038/s41395-018-0262-x

7. Poulsen $\mathrm{CH}$, Eplov LF, Hjorthøj C, et al. Irritable bowel symptoms, use of healthcare, costs, sickness and disability pension benefits: a long-term population-based study. Scand J Public Health. 2019;47:867-875. doi:10.1177/1403494818776168

8. Hausteiner-Wiehle C, Henningsen P. Irritable bowel syndrome: relations with functional, mental, and somatoform disorders. World J Gastroenterol. 2014;20:6024-6030. doi:10.3748/wjg.v20. i20.6024

\section{Linaclotide, plecanatide, and lubiprostone should be considered first- line therapies for IBS-C.}

9. Moayyedi P, Mearin F, Azpiroz F, et al. Irritable bowel syndrome diagnosis and management: a simplified algorithm for clinical practice. United European Gastroenterol J. 2017;5:773-788. doi:10.1177/2050640617731968

10. Zhu S, Wang B, Jia Q, et al. Candidate single nucleotide polymorphisms of irritable bowel syndrome: a [systematic] review and meta-analysis. BMC Gastroenterology. 2019;19:165. doi:10.1186/ s12876-019-1084-z

11. Simrén M, Törnblom H, Palsson OS, et al Visceral hypersensitivity is associated with GI symptom severity in functional GI disorders: consistent findings from five different patient cohorts. Gut. 2018;67:255-262. doi:10.1136/gutjnl-2016-312361

12. Bashashati M, Moossavi S, Cremon C, et al. Colonic immune cells in irritable bowel syndrome: a systematic review and metaanalysis. Neurogastroenterol Motil. 2018;30:e13192. doi:10.1111/ nmo.13192

13. Robles A, Ingles DP, Myneedu K, et al. Mast cells are increased in the small intestinal mucosa of patients with irritable bowel syndrome: a systematic review and meta-analysis. Neurogastroenterol Motil. 2019;31:e13718. doi:10.1111/nmo.13718

14. Bashashati M, Moradi M, Sarosiek I. Interleukin-6 in irritable bowel syndrome: A systematic review and meta-analysis of IL-6 (-G174C) and circulating IL-6 levels. Cytokine. 2017;99:132-138. doi:10.1016/j.cyto.2017.08.017

15. Bashashati M, Rezaei N, Shafieyoun A, et al. Cytokine imbalance in irritable bowel syndrome: a systematic review and meta-analysis. Neurogastroenterol Motil. 2014;26:1036-1048. doi:10.1111/ nmo.12358

16. Sibelli A, Chalder T, Everitt $\mathrm{H}$, et al. A systematic review with meta-analysis of the role of anxiety and depression in irritable bowel syndrome onset. Psychol Med. 2016;46:3065-3080. doi:10.1017/ S0033291716001987

17. Yeh H-W, Chien W-C, Chung C-H, et al. Risk of psychiatric disorders in irritable bowel syndrome-a nationwide, populationbased, cohort study. Int J Clin Pract. 2018;72:e13212. doi:10.1111/ ijcp.13212

18. Duan R, Zhu S, Wang B, et al. Alterations of gut microbiota in patients with irritable bowel syndrome based on 16S rRNA-targeted sequencing: a systematic review. Clin Transl Gastroenterol. 2019;10:e00012. doi:10.14309/ctg.0000000000000012

19. Wang L, Alammar N, Singh R, et al. Gut microbial dysbiosis in the irritable bowel syndrome: a systematic review and meta-analysis of case-controlled studies. J Acad Nutr Diet. 2020;120:565-586. doi:10.1016/j.jand.2019.05.015

20. Barbara G, Grover M, Bercik P, et al. Rome Foundation working team report on post-infection irritable bowel syndrome. Gastroenterology. 2019;156:46-58.e7. doi:10.1053/j.gastro.2018.07.011

21. Klem F, Wadhwa A, Prokop LJ, et al. Prevalence, risk factors, and outcomes of irritable bowel syndrome after infectious enteritis: a systematic review and meta-analysis. Gastroenterology. 2017;152:1042-1054.el. doi:10.1053/j.gastro.2016.12.039

22. Heidelbaugh JJ. These 3 tools can help you streamline management of IBS. J Fam Pract. 2017;66:346-353.

23. American College of Gastroenterology Task Force on Irritable Bowel Syndrome; Brandt LJ, Chey WD, Foxx-Orenstein AE, et al. An evidence-based position statement on the management of irritable bowel syndrome. Am J Gastroenterol. 2009;104(suppl 1):S1-S35. doi:10.1038/ajg.2008.122

24. Menees SB, Powell C, Kurlander J, et al. A meta-analysis of the utility of C-reactive protein, erythrocyte sedimentation rate, fecal calprotectin, and fecal lactoferrin to exclude inflammatory bowel disease in adults with IBS. Am J Gastroenterol. 2015;110:444-454. doi:10.1038/ajg.2015.6

25. Smalley W, Falck-Ytter C, Carrasco-Labra A, et al. AGA clinical practice guidelines on the laboratory evaluation of functional diarrhea and diarrhea-predominant irritable bowel syndrome in adults (IBS-D). Gastroenterology. 2019;157:851-854. doi:10.1053/j.gastro.2019.07.004

26. Markham A. Tenapanor: first approval. Drugs. 2019;79: 1897-1903. doi:10.1007/s40265-019-01215-9

27. Chey WD, Paré P, Viegas A, et al. Tegaserod for female patients suffering from IBS with mixed bowel habits or constipation: a randomized controlled trial. Am J Gastroenterol. 2008;103: 1217-1225. doi:10.1111/j.1572-0241.2008.01808.x

28. Zhou C, Zhao E, Li Y, et al. Exercise therapy of patients with irritable bowel syndrome: a systematic review of randomized controlled trials. Neurogastroenterol Motil. 2019;31:e13461. doi:10.1111/nmo.13461

29. Hustoft TN, Hausken T, Ystad SO, et al. Effects of varying dietary content of fermentable short-chain carbohydrates on symptoms, fecal microenvironment, and cytokine profiles in patients with irritable bowel syndrome. Neurogastroenterol Motil. 2017;29:e12969. doi:10.1111/nmo.12969

30. Zegarac JP. The low-FODMAP diet for IBS: what you need to know. Medscape. August 13, 2019. Accessed September 20, 2021. www.medscape.com/viewarticle/917069

31. Dionne J, Ford AC, Yuan $\mathrm{Y}$, et al. A systematic review and metaanalysis evaluating the efficacy of a gluten-free diet and a low FODMAPS diet in treating symptoms of irritable bowel syndrome: Am J Gastroenterol. 2018;113:1290-1300. doi:10.1038/ s41395-018-0195-4

32. Su H, Li Y-T, Heitkemper MM, et al. Effects of low-FODMAPS diet on irritable bowel syndrome symptoms and gut microbiome: Gastroenterol Nurs. 2019;42:150-158. doi:10.1097/ SGA.0000000000000428

33. Nawawi KNM, Belov M, Goulding C. Low FODMAP diet significantly improves IBS symptoms: an Irish retrospective cohort study. Eur J Nutr. 2020;59:2237-2248. doi: 10.1007/s00394019-02074-6

34. Altobelli E, Del Negro V, Angeletti PM, et al. Low-FODMAP diet improves irritable bowel syndrome symptoms: a meta-analysis. Nutrients. 2017;9:940. doi:10.3390/nu9090940

35. Nagarajan N, Morden A, Bischof D, et al. The role of fiber supplementation in the treatment of irritable bowel syndrome: a systematic review and meta-analysis. Eur J Gastroenterol Hepatol. 2015;27:1002-1010. doi:10.1097/MEG.0000000000000425

36. Wilson B, Rossi M, Dimidi E, et al. Prebiotics in irritable bowel syndrome and other functional bowel disorders in adults: a systematic review and meta-analysis of randomized controlled trials. Am J Clin Nutr. 2019;109:1098-1111. doi:10.1093/ajcn/ nqy376

37. Yuan $\mathrm{F}, \mathrm{Ni} \mathrm{H}$, Asche $\mathrm{CV}$ et al. Efficacy of Bifidobacterium infantis 35624 in patients with irritable bowel syndrome: a meta-analysis. Curr Med Res Opin. 2017;33:1191-1197. doi:10.1080/03007995.20 17.1292230

38. Liang D, Longgui N, Guoqiang X. Efficacy of different probiotic protocols in irritable bowel syndrome: a network metaanalysis. Medicine (Baltimore). 2019;98:16068. doi:10.1097/ MD.0000000000016068

39. Dale HF, Rasmussen SH, Asiller ÖÖ, et al. Probiotics in irritable bowel syndrome: an up-to-date systematic review. Nutrients. 2019;11:2048. doi:10.3390/nul1092048

40. Pratt C, Campbell MD. The effect of Bifidobacterium on reducing symptomatic abdominal pain in patients with irritable bowel syndrome: a systematic review. Probiotics Antimicrob Proteins. 
2020;12:834-839. doi:10.1007/s12602-019-09609-7

41. Ianiro G, Eusebi LH, Black CJ, et al. Systematic review with metaanalysis: efficacy of faecal microbiota transplantation for the treatment of irritable bowel syndrome. Aliment Pharmacol Ther. 2019;50:240-248. doi:10.1111/apt.15330

42. Myneedu K, Deoker A, Schmulson MJ, et al. Fecal microbiota transplantation in irritable bowel syndrome: a systematic review and meta-analysis. United European Gastroenterol J. 2019;7:1033-1041. doi:10.1177/2050640619866990

43. Xu D, Chen VL, Steiner CA, et al. Efficacy of fecal microbiota transplantation in irritable bowel syndrome: a systematic review and meta-analysis. Am I Gastroenterol. 2019;114:1043-1050. doi:10.14309/ajg.0000000000000198

44. Black CJ, Yuan Y, Selinger CP, et al. Efficacy of soluble fibre, antispasmodic drugs, and gut-brain neuromodulators in irritable bowel syndrome: a systematic review and network meta-analysis. Lancet Gastroenterol Hepatol. 2020;5:117-131. doi:10.1016/S2468-1253(19)30324-3

45. Khanna R, MacDonald JK, Levesque BG. Peppermint oil for the treatment of irritable bowel syndrome: a systematic review and meta-analysis. J Clin Gastroenterol. 2014;48:505-512. doi:10.1097/MCG.0b013e3182a88357

46. Alammar N, Wang L, Saberi B, et al. The impact of peppermint oil on the irritable bowel syndrome: a meta-analysis of the pooled clinical data. BMC Complement Altern Med. 2019;19:21. doi:10.1186/s12906-018-2409-0

47. Ford AC, Lacy BE, Harris LA, et al. Effect of antidepressants and psychological therapies in irritable bowel syndrome: an updated systematic review and meta-analysis. Am J Gastroenterol. 2019;114:21-39. doi: 10.1038/s41395-018-0222-5

48. Shah ED, Kim HM, Schoenfeld P. Efficacy and tolerability of guanylate cyclase-c agonists for irritable bowel syndrome with constipation and chronic idiopathic constipation: a systematic review and meta-analysis. Am J Gastroenterol. 2018;113:329-338. doi:10.1038/ajg.2017.495

49. Black CJ, Burr NE, Quigley EMM, et al. Efficacy of secretagogues in patients with irritable bowel syndrome with constipation systematic review and network meta-analysis. Gastroenterology. 2018;155:1753-1763. doi:10.1053/j.gastro.2018.08.021

50. Li F, Fu T, Tong W-D, et al. Lubiprostone is effective in the treatment of chronic idiopathic constipation and irritable bowel syndrome: a systematic review and meta-analysis of randomized controlled trials. Mayo Clin Proc. 2016;91:456-468. doi:10.1016/ j.mayocp.2016.01.015

51. Ford AC, Harris LA, Lacy BE, et al. Systematic review with metaanalysis: the efficacy of prebiotics, probiotics, synbiotics and antibiotics in irritable bowel syndrome. Aliment Pharmacol Ther. 2018;48:1044-1060. doi:10.1111/apt.15001

52. Yoon K, Kim N, Lee JY, et al. Clinical response of rifaximin treatment in patients with abdominal bloating. Korean I Gastroen terol. 2018;72:121-127. doi:10.4166/kjg.2018.72.3.121

53. Black CJ, Burr NE, Camilleri M, et al. Efficacy of pharmacological therapies in patients with IBS with diarrhoea or mixed stool pattern: systematic review and network meta-analysis. Gut. 2020;69:74-82. doi:10.1136/gutjnl-2018-318160

54. Lacy BE. Review article: an analysis of safety profiles of treatments for diarrhoea-predominant irritable bowel syndrome. Aliment Pharmacol Ther. 2018;48:817-830. doi:10.1111/ apt.14948

55. Zheng Y, Yu T, Tang Y, et al. Efficacy and safety of 5-hydroxytryptamine 3 receptor antagonists in irritable bowel syndrome: a systematic review and meta-analysis of randomized controlled trials. PLOS ONE. 2017;12:e0172846. doi:10.1371/journal. pone.0172846

56. Zheng H, Chen R, Zhao X, et al. Comparison between the effects of acupuncture relative to other controls on irritable bowel syndrome: a meta-analysis. Pain Research and Management. 2019;2019:1-13. doi:https://doi.org/10.1155/2019/2871505

57. Yan J, Miao Z-W, Lu J, et al. Acupuncture plus Chinese herbal medicine for irritable bowel syndrome with diarrhea: a systematic review and meta-analysis. Evid Based Complement Alternat Med. 2019;2019:1-16. https://doi.org/10.1155/2019/7680963

\section{(9) Visit us @}

mdedge.com/familymedicine

\section{1) A closer look at the USPSTF draft recs on aspirin}

Doug Campos-Outcalt, MD, MPA

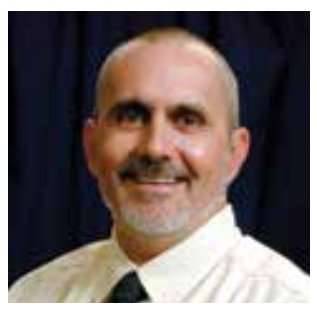

\section{ONLINE EXCLUSIVES}

- CASE REPORT

Successful accelerated taper for sleeping aid

- Dx ACROSS THE SKIN COLOR SPECTRUM Seborrheic dermatitis

- RESIDENTS' RAPID REVIEW

A 5-question monthly quiz to help you prepare for the family medicine (re)certification exam.

This month: Early pregnancy loss

\section{PHOTO ROUNDS FRIDAY}

Test your diagnostic skills at www.mdedge.com/ familymedicine/photo-rounds

\section{PLUS}

Today's headlines in family medicine

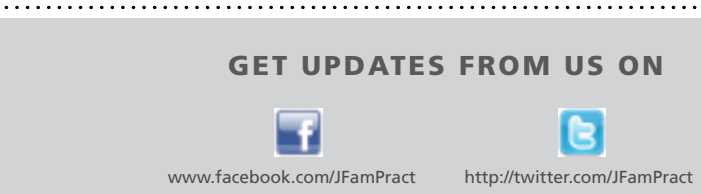

www.mdedge.com/familymedicine 